\title{
Evaluation of Strategies to Increase the Spatial Resolution of X-Ray-Mapping in the FESEM of Low Concentration in Sub-Micron microstructures
}

\author{
Pierre Hovington* Philippe T.-Pinard**, M. Lagacé*, D. Thibault*, L. Rodrigue*, R. Gauvin**, D. \\ Drouin*** \\ * Hydro-Quebec Research Institute, 1800 Lionel-Boulet Boul., Varennes, Quebec, Canada J3X 1S1 \\ ** Materials and Mining Eng. Dept., McGill University, 3610 University St., Montreal, Quebec, Canada H3A 2B2 \\ ***Electrical and Computer Department, U. Sherbrooke, 2500 Boul. U., Sherbrooke Québec, Canada, J1K 2R1
}

Nowadays, the development of new materials most often involves the development of small phases or microstructures $(<<1 \mu \mathrm{m})$ that mainly governs the macroscopic behavior of the materials The characterization of such microstructures, mainly their grain size, distribution and composition, is of prime importance. The Field Emission scanning electron microscope (FESEM) coupled with an energy dispersive spectrometer (EDS) is usually the characterization technique of choice since it allows for the observation of a "large" specimen area compared to the Transmission Electron Microscope (TEM). However, the acquisition parameter must be optimized in order to increase the spatial resolution of the analysis and break the $\mu \mathrm{m}^{2}$ barrier. Several strategies can be used to decrease the X-Rays generation volume. First, one can decrease the beam energy and use the L and M lines in their analysis. Second, one can decrease the overvoltage [1] and use the $\mathrm{K}$ lines. Finally, one can decrease the specimen thickness and work at high energy. All of those strategies will be evaluated both theoretically and experimentally for the analysis of retained austenite in a super-martensitic stainless steel (AISI 415).

We present in Figure 1 a FESEM micrograph showing the residual austenite (RA) found between the martensite lathes. The lamellas are less than $200 \mathrm{~nm}$ in width and have a high Ni concentration (12\% versus $4 \%$ for the martensite matrix). The goal of this work is to do the highest resolution X-ray mapping possible of the RA. We will use several simulation engines (Casino[1], Penelope[2], Oxford spectrum synthesis[3]) to find the best strategy.

In Figure 3, we present the simulated X-ray profile at the edge of the RA for the Ni L and Ni K at 2,5 and $10 \mathrm{kV}$. The graph shows the total detected net intensity per second for a beam of $1 \mathbf{n A}$ for an X-ray detector with a $40^{\circ}$ take off angle and a $14.8 \mathrm{mstr}$ solid angle corresponding to a fully inserted $30 \mathrm{~mm}^{2} \mathrm{Si}(\mathrm{Li})$ detector on a Hitachi $\mathrm{S}-4700$. It is important to note that, usually, only relative X-ray intensity is reported from simulation programs. The detector efficiency is taken from nominal transmission from Moxtek AP3 window combining film and grid $(25 \%$ for Cr L and $77 \%$ for $\mathrm{Cr} \mathrm{K}$ ). We also computed the minimum intensity $\left(\mathrm{I}_{\min }\right)$ to get a meaningful statistical peak $\mathrm{I}_{\min }=3 *\left(2 \mathrm{I}_{\mathrm{BG}}\right)^{1 / 2}$, where $\left(\mathrm{I}_{\mathrm{BG}}\right)$ is the background intensity under the peak calculated using a spectrum synthesis form Oxford and an "inhouse" deconvolution program. In Figure 4, we compared the Casino and PENELOPE results. It is very interesting to note that the net intensity (not relative intensity) is very similar for all the simulation programs used even though they use very different physics. PENELOPE's intensity seems to be higher than Casino most probably because of the choice of X-ray cross-sections (Casnati for Casino and Bote [5] for PENELOPE-2008). Figure 3 and 4 clearly shows that, at 1 sec acquisition time, the $\mathrm{Ni} \mathrm{K}$ lines at low overvoltage and the $\mathrm{Ni} \mathrm{L} \mathrm{at} 2 \mathrm{kV}$ are too close to their minimum values. The best solution would be to use the $\mathrm{Ni} \mathrm{L}$ at $5 \mathrm{kV}$.

We present in Figure 2 simulations of the Ni K X-ray signal coming from high energy electrons hitting a thin film showing an optimum spatial resolution for a $100 \mathrm{~nm}$ thick film and a $30 \mathrm{kV}$ beam of $1 \mathrm{~nm}$ size. Using thinner sample only decrease the detectable Ni K intensity However, the Ni L X-ray count rate coming from a bulk sample is more than two times higher at $5 \mathrm{kV}$ (cf. Figure 3) but the spatial resolution is lower. Both acquisition conditions will be experimentally tested.

In conclusion, using simulations (first principles and Monte Carlo) to compute the net detected intensity is a powerful technique to find the optimal experimental conditions to obtain X-ray mapping with the best energy resolution. It was found that, for our low $\mathrm{Ni}$ concentration system, performing the analysis at $30 \mathrm{kV}$ on a $100 \mathrm{~nm}$ thick sample gives the best spatial resolution. However, better counting statistics can be obtained from a bulk sample at $5 \mathrm{kV}$. Using the $\mathrm{K}$ lines at low overvoltage $(\sim 1.2)$ seems to give low counts rates.
Comment [PP1]: Mainly?

Comment [VN2]: Où sont les résultat expérimentaux?

Comment [PP3]: Peut-être mentionné le beam diameter..

Comment [PP4]: 30 ou 40

Comment [PP5]: Ils l'écrivent toujours en majuscules

Comment [VN6]: spatial 


\section{References}

[1] Newbury, Microsc. Microanal. 8 (Supp 2), pp. 434-435 (2002)

[2] Hovington et al, Scanning, Vol 19, pp.1-14 (1997),

[3] Baró, et al., Matter Nuclear Instruments and Methods in Physics Research B, 1995, 100, pp. 31-46

[4] INCA is a trademark of Oxford Instrument] (Patent EP1736759)

[5] Bote, D et al . Journal of Physics D: Applied Physics, v 41, n 10, 21 May 2008, 105304 (9 pp.)

\section{Field Code Changed}

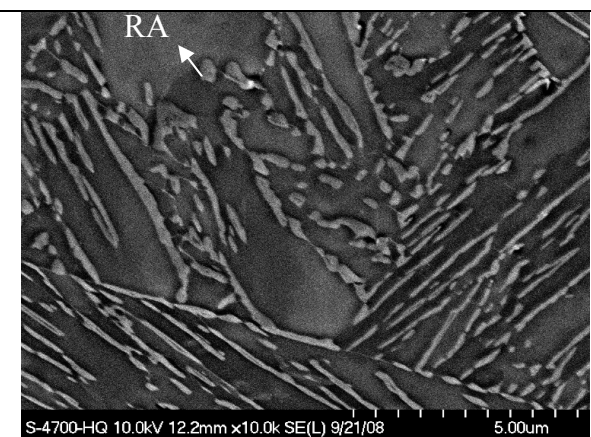

Figure 1 Typical electron micrograph of supermartensite stainless steel showing the Residual Austenite (RA)

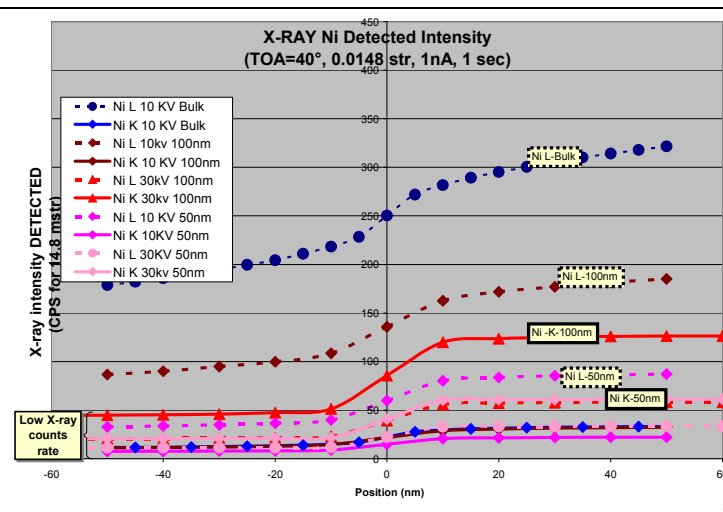

Figure $2 \mathrm{Ni} \mathrm{X}$-ray detected counts for $1 \mathrm{sec}$ and $1 \mathrm{nA}$ at high energy $(10$ and $30 \mathrm{kV})$ for bulk and thin sample $(100 \mathrm{~nm}$ and 50 $\mathrm{nm})$. We used a $5 \mathrm{~nm}$ and $1 \mathrm{~nm}$ beam diameter for the simulation at $10 \mathrm{kV}$ and $30 \mathrm{kV}$ respectively.

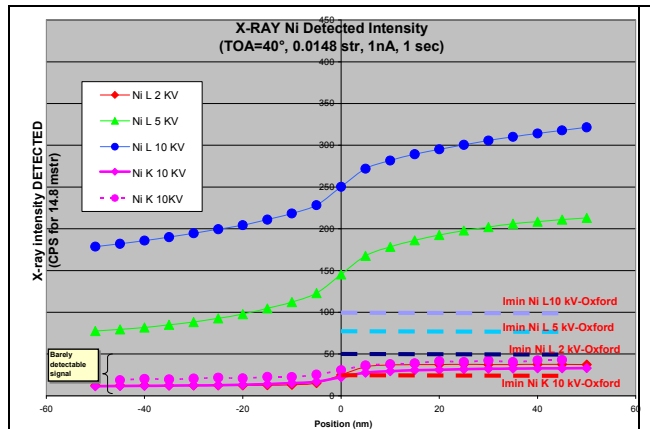

Figure 3: Ni X-ray detected counts for $1 \mathrm{sec}$ and $1 \mathrm{nA}$ at low energy $(2,5$ and $10 \mathrm{kV})$ for a bulk sample using Casino. We also present the minimum detectable intensity for $\mathrm{Ni} \mathrm{L}$ and $\mathrm{Ni} \mathrm{K}$. We used a $5 \mathrm{~nm}$ probe diameter at $2 \mathrm{KV}$ and $5 \mathrm{kV}$.

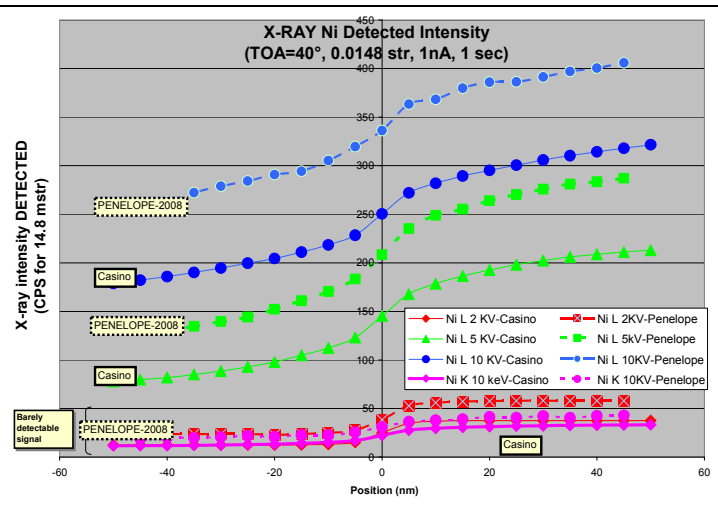

Figure 4: Ni X-ray detected count for $1 \mathrm{sec} 1 \mathrm{nA}$ at low energy $(2,5$ and $10 \mathrm{kV})$ for a bulk sample using the Casino and Penelope simulation engines. We used a $5 \mathrm{~nm}$ probe diameter at $2 \mathrm{KV}$ and $5 \mathrm{kV}$. PENELOPE simulations used single point electron beam. 